\title{
La manipulación de la identidad y perfiles virtuales en las redes sociales
}

A manipulação de identidade e perfis virtuais nas redes sociais

Manipulation of identity and virtual profiles in social network

\author{
María Beatriz JUÁREZ ESCRIBANO \\ Universidad Nebrija - España \\ mjuareze@nebrija.es \\ Lidia MAÑOSO PACHECO \\ Universidad Autónoma - España \\ lidia.mannoso@uam.es
}

Chasqui. Revista Latinoamericana de Comunicación

N. ${ }^{\circ}$ 147, agosto-noviembre 2021 (Sección Monográfico, pp. 69-8o)

ISSN 1390-1079 / e-ISSN 1390-924X

Ecuador: CIESPAL

Recibido: 30-11-2020/Aprobado: 10-07-2021 


\title{
Resumen
}

Los acontecimientos de la vida están formados por las prácticas sociolingüistas y culturales del grupo social al que pertenecemos, formando así nuestra identidad. Debemos tener cuidado en no mostrar aquellas diferencias que no son toleradas por dicho grupo para evitar conflictos, manipulando la verdad. Para evidenciar este comportamiento hemos empleado un muestreo no probabilístico por cuotas basado en los test científicos NeoPi-R y Millon. Los resultados señalan que el $80 \%$ de los individuos prefiere mantener su verdadera identidad al margen y no ser sincero con el resto.

Palabras clave: autopresentación, comportamiento, redes sociales, sociedad.

\begin{abstract}
Our life events are made up of sociolinguistic and cultural practices of our group, thus shaping our identity. We should be careful not to show those differences that are not accepted by the group to avoid conflicts, manipulating the truth. To provide evidence of this behaviour, we have applied a non-probabilistic quota sampling based on Neo Pi-R and Millon tests. The results show that the $80 \%$ of individuals prefer keeping their true identity apart and not being sincere with the rest.
\end{abstract}

Keywords: self-presentation, behaviour, social networks, society.

\section{Resumo}

Os acontecimentos da vida são moldados pelas práticas sociolingüísticas e culturais do grupo social ao qual pertencemos, formando assim nossa identidade. Devemos ter o cuidado de não mostrar aquelas diferenças que não são toleradas por tal grupo para evitar conflitos, manipulando a verdade. Para demonstrar esse comportamento, usamos uma amostra não probabilística de cotas com base nos testes científicos NeoPi-R e Millon. Os resultados indicam que $80 \%$ dos indivíduos preferem manter sua verdadeira identidade de lado e não ser sincero com os demais.

Palavras-chave: auto-apresentação, comportamento, redes sociais, sociedade. 


\section{Introducción}

El ser humano independiente y aislado no puede evolucionar. Es la interacción social en general y sus conexiones sociales en particular lo que le da su naturaleza humana.

A priori, los individuos de una sociedad tienen valores comunes (raza, lengua, religión, historia cultural, tradición, etc.). Lo habitual es que el individuo se adscriba naturalmente a los grupos predominantes en su entorno social (por ejemplo: cristianos, hispanoparlantes, demócratas, entre otros) (Juárez, 2018), por lo que "el individuo, pues, construye su identidad social a través de la adhesión" a esos grupos (Pinxten, 1997, p. 43). Cada uno de ellos incorpora a la persona un conjunto de informaciones y valores que moldean su personalidad.

Tradicionalmente, el concepto de identidad aparece ligado al de personalidad, confundiéndose a veces, o más habitualmente entendiéndose aquella como parte integrante de esta. La idea de identidad como tal, a su vez, ha ido recibiendo diversas denominaciones en otras tantas teorías. En el presente estudio, aceptaremos que la identidad es parte de la personalidad, tal y como señala el profesor Bernal, quien afirma que "la identidad personal es una parte de la personalidad, esa parte que podemos imaginar, inventar, crear y escoger" (2005, p. 97). También así lo acepta Carl Gustav Jung (2002) al afirmar que el yo (la parte de la psique que selecciona las percepciones, pensamientos, sentimientos y recuerdos que llegan a la consciencia) es el responsable de nuestra sensación de identidad. Así, para iniciar nuestra aproximación al concepto de identidad, empezaremos por el más global, de personalidad.

Hasta la década de los años 30 del siglo pasado, no se considera a la personalidad como un área específica de estudio dentro de la psicología. Tal reconocimiento implica que la existencia de la personalidad es un hecho aceptado científicamente. Desde entonces, el estudio de la personalidad (y de la identidad) ha generado diversas teorías, surgidas habitualmente de un supuesto filosófico inicial, el cual

se intenta probar como acertado por medio de la investigación científica (Engler, 1996).

Algunas de estas teorías son semejantes entre sí, otras complementarias y algunas incluso contrarias. Cada una hace hincapié en unos u otros aspectos (libertad o determinismo, ambiente o herencia, optimismo o pesimismo). Muchas han sido revisitadas o reformuladas, sirviendo de base para otras posteriores. Existe así una cierta unidad de fondo, puesto que, aunque cada autor emplee distintas terminologías, estas suelen referirse a los mismos o similares conceptos. Por eso, pese a la multiplicidad de formulaciones teóricas, podemos encontrar puntos de partida y elementos comunes que caracterizan a muchas de ellas.

En lo referente a la personalidad, hemos escogido una serie de elementos que se adecuan bastante bien al propósito de nuestro estudio, siguiendo a varios 
autores (Rousseau, 1994; Hall, 2003; Álvarez, 2008; Lipovetsky, 2009; Faerman, 2010; Juárez, 2018). Esos elementos son los siguientes:

- Carácter evolutivo.

- Aceptación social y adaptación al entorno.

- Expresión variable de la propia identidad.

- "Armonización en un todo continuo de las distintas etapas que se atraviesan en la formación de la identidad” (Juárez, 2018, p. 279).

La identidad permite al hombre percibirse a sí mismo como individuo separado y presentarse así ante los demás y ante el mundo. Que los otros acepten nuestra identidad, que no es sino la propuesta que hacemos de nosotros mismos, es lo que la hace válida, en tanto que se conforma como una herramienta necesaria para cualquier interacción vital.

De acuerdo con Pinxten, comenzamos aceptando que la identidad social está condicionada por el entorno y no por la genética, como postulan los ambientalistas "quienes esgrimen una pléyade de factores hereditarios, raciales y genéticos para explicar las diferencias y semejanzas (socio)culturales” (Harris, 2004, p. 39).

Aceptar unos presupuestos iniciales tan rígidos, como que la identidad individual o social está determinada por la dotación genética en lugar de verse moldeada en buena medida por el entorno, el azar y las vivencias concretas del individuo, haría que el papel de los objetos de pensamiento sociológico fuera muy limitado a la hora de determinar cómo influye la interacción entre grupos en la identidad del individuo. De ello ya habló Schelling en su publicación Modelos dinámicos de segregación, donde exponía un patrón espacial en el que la población se distribuye según las preferencias de composición de sus vecinos circundantes (Schelling, 1971).

Por otra parte, cuando entramos en un grupo desconocido acogemos sus reglas rápidamente, de manera instintiva y poco crítica pues lo único que nos interesa, como decíamos, es ser aceptados. El objetivo de la presente investigación es, por tanto, analizar cómo los usuarios de redes sociales alteran y manipulan su identidad virtual para poder ser reconocidos y aprobados en esos grupos virtuales, publicando diferente tipo de información según la red social que utilicen.

Llevado al plano digital, los cibernautas suelen publicar dos tipos de conductas principalmente en sus redes sociales: las de satisfacción, que suelen ser la mayoría, pero también de frustración. Las primeras son utilizadas para mostrar a otros lo felices que son en su vida, ya que, como dice el psicólogo Jordan, siempre "queremos ser más felices que el resto, (aunque) resulta complicado porque (a los demás) nos los imaginamos más contentos de lo que están (realmente)" (Jordan et al., 2010, p. 127). Se produce así un doble engaño debido a que, por un lado, engaña el que publica una conducta de satisfacción 
ya que tiende a exagerar y, por otro, se engaña el que lo lee porque enfatiza demasiado el mensaje de su amigo, haciéndole sentir mal por no poder alcanzar su mismo estado de alegría y felicidad. En cuanto a las conductas de frustración son muy empleadas sobre todo por aquellos jóvenes que afirman no encontrar su sitio en la sociedad, reflejando una sensación de fracaso constante por no encajar en ningún grupo o no sentirse aceptado (Twenge, 2018). Debemos mencionar aquellas personas que utilizan esta táctica para, simplemente, llamar la atención y reclamar cierto protagonismo en las redes (Dimitroff et al., 2019).

Por todo ello, partimos de la hipótesis general de que las personas que acceden a las redes sociales cambian y adaptan su identidad virtual a través de la conducta para sentirse parte de la comunidad a la que se adscriben. De esta forma, su autopercepción permanece estable y el individuo se siente aceptado.

Sea como sea la conducta del sujeto, individuo y sociedad son dos entes indivisibles. No podemos aislar las variables particulares de las sociales porque aislándolas las corromperíamos por completo. Hay muchos elementos en la identidad que son sociológicos y resulta imposible separarlos del individuo, que a nuestro juicio es psicosocial.

\section{Marco teórico}

Tal y como señala Trapero (1984) y Toro (2008), la base de la ciencia semiótica (el signo), es la situación dramática o la unidad performativa, es decir, la puesta en escena. Esta ha sido definida de dos formas diferentes. La primera fue propuesta por Ferdinand De Saussure (1975, p. 127-129), quien imaginó el signo lingüístico como una entidad dual:

Hecha con la unión de dos términos [...] lo que el signo une no es una cosa y un nombre, sino un concepto y una imagen [...] proponemos conservar la palabra signo para designar el conjunto y reemplazar conceptos e imagen [...] respectivamente por significado y significante.

La segunda definición viene dada por el americano Charles S. Peirce, quien plantea la definición de signo como una triple entidad formada por un vehículo de signo, un interpretante y el objeto (Pierce, 1974). A diferencia de Saussure:

El signo peirceano no es exclusivamente lingüístico, sino que se extiende a fenómenos no lingüísticos, sobre todo visuales; su estudio, la ciencia semiótica, ya no formaría parte de la psicología social sino de la Lógica y, por inclusión, de la Ciencia. (Trapero, 1984, p. 131)

Además, ambas teorías han desarrollado tres escuelas semióticas: la semiótica de la comunicación (que es la que usaremos de base para este estudio), la de la significación y la de la producción. La semiótica de la comunicación 
constituye la primera limitación en el campo semiótico, ya que lo reduce al estudio de los fenómenos con intención comunicativa por parte del emisor, y reconocida como tal por el receptor (Buyssens, 1978). Esto puede provocar, tal y como señala Umberto Eco, que "no se admita la intencionalidad como algo infalible, ya que puede ser falseada por el emisor o malinterpretada por el receptor" (Trapero, 1984, p. 132).

\subsection{La tecnología de la información y la sociedad. Goffman y la autopresentación}

La emergente realidad virtual trastorna nuestra manera de entender el mundo y, lo que es más esencial, hace variar nuestro sentido de la identidad (Macionis \& Plummer, 2011).

Debido a esta ubicuidad y a la velocidad de propagación de información en la red, el internauta deja una impresión en la red visible para todo el público (suponiendo un perfil abierto) que, al verlo, puede optar por pulsar el icono de me gusta, seguir a esa persona, comentar la fotografía o realizar las tres cosas. A su vez, esta acción es visible para los contactos del reciente integrante o comentarista, y así sucesivamente. De esta forma, estamos provocando una serie de reacciones en cadena que, por efecto arrastre, moviliza a gran cantidad de personas cuyo motivo, muchas veces, es el simple hecho de sentir que pertenecen a esta corriente que está de moda, aunque no les guste realmente (Smith \& Jacobsen, 2019).

A cada situación social le corresponde un guion que más o menos siluetea lo que se supone que ha de ocurrir y los papeles que son necesarios representar. La manipulación de esta representación se produce constantemente y es aceptada por todos los intervinientes.

El puzle de la interacción social encaja porque los demás suelen acompañar nuestra propia actuación, aun cuando saben que es inventada. ¿Significa esto que la mayor parte de nuestra conducta es mera impostura y representación, y que la cara que presentamos a los demás es una máscara? No necesariamente (Calhoun, Light \& Keller, 2000). Pirandello (2000) señala que "los personajes reales no tienen cabida en el escenario, solo la tienen los actores que los representan" (citado en Navarro, 2008, p. 36). Pero cuanto más representamos un papel, más auténticos nos sentimos hasta que estamos casi tan convencidos como nuestro público de que somos lo que pretendemos ser.

Goffman (1959) elabora la teoría de la autopresentación, pero poniendo énfasis en este enfoque dramatúrgico. Acuña el término autopresentación o manipulación de la presentación "para describir los esfuerzos de las personas por controlar lo que otros piensan de ellos" (Calhoun et al., 200o, p. 82). Esto ocurre en las redes sociales virtuales cuando, por ejemplo, pensamos qué poner en el muro sin ofender a ninguno de nuestros amigos. Goffman cree que la representación exitosa de nuestro propio papel (modificando nuestro 
significante real) depende de que los demás asuman papeles complementarios que den la respuesta adecuada y esperada en cada momento (1959). Todos actúan como si las representaciones de los demás fuesen legítimas y verdaderas, porque ocultamos parte de nuestro significado en ciertos momentos.

En la red (o, como diría Goffman, en escena) podemos incluso dejar de ser nosotros mismos y crear una identidad (significante inventado o no), ya que detrás de la pantalla nadie nos ve.

\subsection{Los estigmas desacreditables y desacreditados}

En la obra Stigma, Goffman se enfoca en la brecha que "tiene lugar entre lo que una persona debería ser, su identidad social virtual, y lo que una persona verdaderamente es, su identidad social real. Todo aquel que experimenta un altibajo entre estas dos identidades está estigmatizado" (1963, p. 12). Precisamente en las redes sociales se suele volcar más la primera. El individuo busca tener sus identidades lo más próximas posibles, y la mejor manera de conseguirlo es crear una identidad virtual en la red.

Goffman (1963) señala dos tipos de estigmas: el desacreditable y el desacreditado. Un estigma desacreditable se produce cuando las diferencias no son reconocibles o visibles para los miembros de la representación. Para alguien señalado con un estigma desacreditado, la cuestión reside en saber llevar la tensión que desencadena el hecho de que el estigma resulta evidente en el acto (por ejemplo, una persona que tiene una disminución física). Para el que sufre un estigma desacreditable, la dificultad dramática estriba en saber manejar la información de tal forma que el inconveniente siga escondido para la audiencia. Así, por ejemplo, debemos tener cuidado en no mostrar nuestros estigmas desacreditables, es decir, aquellas diferencias que no son reconocibles por los demás miembros de la representación, y que queremos mantener ocultas.

Goffman (1963) intenta transmitirnos la idea de que todos estamos estigmatizados realmente.

\section{Método empleado}

En esta investigación de corte transversal se utilizó un muestreo no probabilístico por cuotas. Los individuos valorados entre los meses de febrero y marzo de 2019, debían tener edades comprendidas entre 16 y 65 años, poseer al menos un título en formación secundaria, tener perfil en alguna red social y ser activos de las mismas. El tamaño muestral estuvo conformado por 100 miembros hispanohablantes. Del total de participantes, 35\% eran hombres y el resto mujeres (65\%). El 52,5\% se situaba entre los 35 y 65 años de media y un $93 \%$ era poseedor de un título universitario.

Para comprobar nuestra hipótesis este muestreo se fundamenta en una encuesta online basada en los test NeoPi-R (Neuroticism-Extroversion- 
Openness Personality Inventory Revised ${ }^{1}$ ), y Millon, este último adaptado por Solé (2006), donde ambos abarcan diversos campos y variables en la evolución de la personalidad. El NeoPi-R es un cuestionario llevado a la práctica por Costa y McCrae (1992) que evalúa a través de 240 ítems el Modelo de los Cinco Factores de Personalidad y sus facetas correspondientes a cada uno de ellos. El Modelo de los Cinco Factores (Ross et al., 2009) demuestra que de las cinco dimensiones que forman la personalidad (extraversión, amabilidad, responsabilidad, neurosis y apertura a la experiencia), tres de ellas afectan a la participación en las redes sociales (extraversión, neurosis y apertura a la experiencia) (Correa, Hinsley \& Zúñiga, 2010, p. 248).

Nuestro cuestionario online está estructurado a partir de preguntas cerradas, de respuesta simple y múltiple, combinadas con escalas Likert, con el fin de conseguir información sobre cómo adaptamos nuestra conducta en las redes sociales para sentirnos integrados en ellas. Se estructura de la siguiente manera:

Variables demográficas y propiedades de la personalidad: para averiguar las cualidades de la personalidad hemos utilizado el test avalado científicamente NeoPi-R en una escala de diferencial semántica de cinco puntos (marcadores bipolares) utilizada por Goldberg (1992) y adaptada por Solé (2006). Este test ayuda a los encuestados a identificar sus principales rasgos (extraversión, amabilidad, responsabilidad, neurosis y apertura a la experiencia), y esto nos favorecerá detectar qué tipo de personalidad emplean los internautas en las redes sociales.

Adopción de redes sociales virtuales: almacena preguntas concernientes al uso de estas: experiencia, razones para participar, tipo de perfil (público/ privado, activo/pasivo), contactos, rutinas y privacidad. Esta parte señala si el individuo se siente o no aceptado en estas redes (sociología), y si su uso sigue un patrón cultural (rutinas, costumbres, motivos por los que se usa esa red social).

Estados internos del individuo: recoge preguntas cerradas (verdadero/falso) del Inventario de Personalidad de Millon (1990), adaptadas a nuestro informe. Escogimos concretamente las siguientes preguntas: 21: "Tengo más amigos de los que puedo atender"; 54: "Estoy siempre metido/a y ocupado/a en muchas actividades sociales"; 59: "Con frecuencia dudo de que la gente esté interesada de verdad que lo que yo les digo"; 77: "Soy el tipo de persona teatral a la que le gusta llamar la atención"; 80: "Preferiría ser claro con la gente en vez de callarme lo que sé que no les gusta”; 90: "Me dejo influir fácilmente por los demás”; y 105: "Me gusta contarle a otros las cosas que he hecho bien" (Millon, 1990, citado en Alarcón, 2011, p. 449-457).

1 Aunque actualmente el término NEO ya no se considera un acrónimo sino parte del nombre del test. 


\section{Discusión y resultados}

En los resultados hemos utilizado análisis descriptivos univariables (porcentajes) para determinar la muestra, y multivariantes para comprobar el nexo entre variables.

El perfil sociodemográfico mayoritario que encontramos en las redes sociales es el de mujer con formación universitaria que se sitúa en un rango de edad de entre 35 y 65 años (52\%). Examinando el primer bloque del cuestionario que define la autopercepción de los rasgos de los individuos (extraversión, amabilidad, responsabilidad, neurosis y apertura a la experiencia), todos los encuestados dicen sentirse seguros de ello. El $45 \%$ se considera sobre todo enérgico, activo y sociable, y un $47 \%$ cree que es más osado. Como contraste encontramos que un $72 \%$ dice ser bastante neurótico.

La mayoría de las personas encuestadas afirma ser consumidora de diferentes redes sociales $(76,9 \%)$, siendo el nivel de veracidad de los datos que comparte bastante alto $(64,6 \%)$. No obstante, observamos que el estado civil apenas se comparte (un $66 \%$ no lo hace), el $32 \%$ afirma no publicar su edad, y el $26 \%$ cambia su nombre dependiendo de la red que utilice.

En cuanto al comportamiento que manifiestan los internautas en las redes, sí que observamos diferencias en función del grupo con el que interactúan. Un $49,2 \%$ admite portarse de manera diferente dependiendo de la red social que utilice, mientras que la otra mitad indica que actúa siempre del mismo modo.

Respecto a la creación de segundos perfiles en una misma red social, el $45 \%$ admite tenerlos, y de ese $45 \%$ casi un $30 \%$ afirma que estos perfiles son inventados, es decir, no coinciden con su identidad real, creando un alter ego.

Estos resultados nos revelan una particularidad muy significativa, y es que se comprueba que se produce un gran contraste entre la autopercepción de su metaidentidad (el estado interno del individuo) y el comportamiento de las personas cuando actúan en función de una tercera. La autopercepción que tienen los internautas de ellos mismos "es más continua ya que son conscientes y reconocen por completo su metaidentidad, aspecto que no ocurre con la heteropercepción" (Juárez, 2014, p. 362). Los individuos suelen mostrar más inseguridad con respecto a lo que creen que los demás piensan de ellos, "llegando incluso a engañar en sus estados o perfiles para crear una mejor impresión o parecer más interesantes" (2014, p. 362).

En el tercer bloque "Estados internos del individuo", a la pregunta de si dudan que la gente esté interesada sinceramente en lo que ellos publican en las redes, encontramos que el $67,7 \%$ piensa que lo que publica no interesa al resto de miembros mientras que un $32,3 \%$ opina que sí.

Por otro lado, un 96,9\% afirma que se manifiesta en las redes sociales tal cual es, resultado que contrasta significativamente con los resultados de la siguiente pregunta: "en ocasiones preferiría ser más sincero con la gente y manifestarme tal cual soy", donde un $80 \%$ asegura que prefiere mantener su verdadera 
identidad al margen y no ser sincero con el resto de individuos. Encontramos, por tanto, una clara contradicción, y vemos cómo la mayoría prefiere mentir en su identidad para poder encajar mejor en los grupos a los que se adscriben.

La autopercepción social que tienen los sujetos respecto a si se adaptan fácilmente a los gustos e intereses de los demás en las redes también está claramente dividida, ya que de los 65 encuestados el 38,5\% así lo cree, mientras que el resto afirma no dejarse influir. Este resultado vuelve a contrastar con la siguiente pregunta: "en las redes sociales cuento lo bueno con mayor frecuencia que lo malo", ya que casi el 60\% admite publicar con mayor frecuencia las vivencias positivas que les van sucediendo.

Por último, encontramos una segmentación casi perfecta a la pregunta de si les preocupa lo que otros contactos puedan publicar de ellos en Internet. Un 50,8\% afirma preocuparles, mientras que al resto no parece importarles.

\section{Conclusiones}

Como conclusiones principales podemos afirmar que la semiótica de la comunicación teatral, y más concretamente la visión de Goffman, dan un paso más tomando como base esta manipulación que hacemos en la vida, cambiando nuestro significado y el significante, y dándole un enfoque dramatúrgico. La representación que hacemos de nuestro propio papel no solo depende de nosotros mismos, sino también de los demás, ya que tienen que asumir roles complementarios para obtener las respuestas esperadas en cada situación. Goffman afirma que la identidad es producto de la interacción entre el actor y su audiencia. Las personas pretenden, por lo general, presentar a los demás una imagen idealizada de sí mismas (cambian su significante), y eso supone ocultar determinadas cosas en sus actuaciones (esconden el significado de su original significante). Lo mismo ocurre en las redes sociales virtuales cuando, por ejemplo, solo mostramos las cosas agradables que nos suceden.

Creamos y formamos parte de grupos con gustos similares, y un porcentaje de nuestra identidad social viene definido por la pertenencia a esos grupos sociales, y las derivaciones psicológicas o emocionales de esa pertenencia. Por lo tanto, si nos sentimos cómodos en esos grupos permanecemos en ellos, bien porque nos guste la oferta que brinda ese grupo, bien porque, aunque nos haya dejado de gustar, seguimos obteniendo algún beneficio de él.

Tenemos que adecuar permanentemente "nuestra conducta a lo que esperan los demás, y nuestra acción debe ser continuamente revisada en función de la respuesta de los otros individuos" (Juárez, 2020, p. 311). Aunque sea un rol repetitivo y bien conocido, necesita ser continuamente recreado a través de la acción. Por eso llegamos a la conclusión de que también una parte de nuestra identidad virtual estaría definida por lo que opinan de nosotros en Facebook, Instagram, LinkedIn, u otras redes sociales virtuales. De este modo, construimos imágenes de los demás y de nosotros mismos de un modo que nos 
ayuda a volver estable y predecible el mundo social que nos rodea. Tendemos a formarnos impresiones cuando, por ejemplo, estamos con otras personas y buscamos señales o signos que nos den información sobre ellos (sus roles principales, su clase social, sus perfiles, etc.).

\section{Referencias bibliográficas}

Alarcón, M. C. (2011). Adopción de las redes sociales virtuales: un enfoque transcultural (Tesis doctoral). Universidad de Castilla la Mancha.

Álvarez, A. (2008). Conferencia abierta: La construcción de la identidad, fallas en la consolidación del sentimiento de sí mismo: la identidad negativa. Recuperado de http:// bitly.ws/fJ2F

Bernal, A. (2005). Reconceptualización de la identidad personal y educación para la autodeterminación posible. Revista interuniversitaria Teoría de la educación, 17.

Buyssens, E. (1978). La comunicación y la articulación lingüística. Buenos Aires: Eudeba.

Calhoun, C., Light, D., \& Keller, S. (2000). Sociología. Madrid: McGraw Hill.

Correa, T., Hinsley, A., \& Zúñiga, H. (2010). Who interacts on the Web? The intersection of users personality and social media use. Computers in Human Behavior, 25, 247-253.

Costa, P., Mc, \& Crae, R. (1992). Revised NEO personality inventory (NEOPIR) and the NEO Five-Factor inventory (NEO-FFI). Professional manual. Florida: Psychological Assessment Resources Inc.

Dimitroff, S. J., Harrod, E. G., Smith, K. E., Faig, K. E., Decety, J., \& Norman, G. J. (2019). Castigos de terceros tras el rechazo social observado. Madrid: American Psychological Association. http://dx.doi.org/10.1037/emooooo607

Engler, B. (1996). Introducción a las teorías de la personalidad. Ciudad de México: Mc Graw Hill.

Faerman, J. (2010). Faceboom, facebook, el nuevo fenómeno de masas. Barcelona: Alienta.

Goffman, E. (1959). The presentation of self in everyday life. Recuperado de https://bit. ly/38MJRqf

Goffman, E. (1963). Estigma. La identidad deteriorada. Buenos Aires: Prentice Hall.

Goldberg, A. L. (1992). The mechanism and functions of ATP-dependent proteases in bacterial and animal cells. European Journal of Biochemistry, 203(1-2), 9-23.

Hall, S. (2003). ¿ Quién necesita identidad? Buenos Aires: Amorrortu.

Harris, M. (2004). Teorías sobre la cultura en la era posmoderna. Madrid: Biblioteca de Bolsillo.

Jordan, A. H., Monin, B., Dweck, C. S., Lowet, B. J., John, O. P., \& Gross, J. J. (2010). La miseria tiene más compañía de la que piensa la gente: subestimar la prevalencia de las emociones negativas de los demás. Personalidad y psicología social, 37(1), 120-135. http:// dx.doi.org/10.1177/0146167210390822

Juárez, M. B. (2014). Las redes sociales virtuales como medios de comunicación de masas. Autopercepción y comportamiento de usuarios [tesis de doctorado no publicada]. Universidad Camilo José Cela.

Juárez, M. B. (2018). La identidad individual, social, cultural y virtual en las redes sociales: autopercepción y comportamiento de los usuarios. En S. Morales, \& F. Vidal (Ed.), Nuevo paradigma comunicativo. Lo 2.0, 3.0 y 4.0 (p. 277-289). Barcelona: Gedisa.

Juárez, M. B. (2020). Análisis de la cultura virtual en las redes sociales como organización 
digital. Revista Prisma Social, 30, 296-321.

Jung, C. G. (2002). El hombre y sus símbolos. Barcelona: Caralt.

Lipovetsky, G. (2009). La era del vacío. Barcelona: Anagrama Colección Compactos.

Macionis, J. J., \& Plummer, K. (2011). Sociología. Madrid: Pearson Educación.

Millon, T. (1990). Toward a new personology: An evolutionary model. Nueva York: John Wiley and son.

Navarro, M. T. (2008). Luigi Pirandello. Seis personajes en busca de autor. Madrid: Biblioteca Edaf.

Peirce, C. S. (1974). La ciencia de la semiótica. Buenos Aires: Nueva Visión.

Pinxten, R. (1997). Identidad y conflicto: personalidad, socialidad y culturalidad. Cidob d'afers internacionals, 36, 39-57.

Pirandello, L. (2000). Seis personajes en busca de autor. Madrid: Editorial Edaf.

Ross, C., Orr, E., Sisic, M., Arseneault, J. M., Simmering, M., \& Orr, R. (2009). Personality and motivations associated with Facebook use. Computers in Human Behavior, 25, 578-586.

Rousseau, J. (1994). El contrato social. Barcelona: Edicomunicación.

Saussure, F. (1975). Curso de Lingüistica general. Buenos Aires: Losada.

Schelling, T. C. (1971). Models of segregation. American economic review, 59(2), 488-493.

Smith, G., \& Jacobsen, M. (2019). Interaccionismo crítico y cultural. Perspectivas de sociología $y$ criminología. Nueva York: Taylor \& Francis.

Solé, M.D (2006). Validació i estandardització espanyola del NEO-PI-R, NEOFFI, NEO-FFI-R i escales de Schinka, en mostres universitàries I población general (Tesis doctoral). Universidad de Lleida.

Toro, F. (2008). Semiótica del teatro: del texto a la puesta en escena. Buenos Aires: Galerna.

Trapero, P. (1984). Aproximación a la semiótica teatral. Madrid: Caligrama.

Twenge, J. (26 de enero de 2018). ¿Las redes sociales nos hacen infelices? Recuperado de https://bit.ly/36Hp5q5 